\title{
La construcción de la identidad en el periodismo literario de Juan José Millás: el caso Nevenka Fernández
}

\section{The construction of identity in Juan José Millás’ literary journalism: the Nevenka}

Fernández case

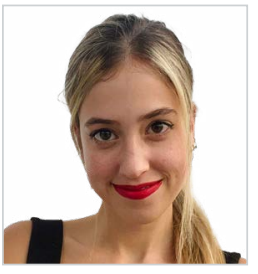

Paula Fuentes Hernández. Graduada en Español: Lengua y Literatura, cursó durante 2018 y 2019 el Máster de Investigación en Periodismo: Discurso y Comunicación con el objetivo de profundizar en su línea de investigación principal, basada en el análisis de las fronteras existentes entre el periodismo y la literatura. Actualmente ingresa en la Escuela de Doctorado de Periodismo de la Universidad Complutense de Madrid, donde se encuentra elaborando una tesis dedicada al reporterismo de Juan José Millás en prensa escrita.

Universidad Complutense de Madrid, España

paufue02@ucm.es

ORCID: 0000-0001-7548-2305

Recibido: 13/09/2021 - Aceptado: 23/12/2021 - En edición: 28/12/2021 - Publicado: 01/01/2022 Resumen:

En la prolífica trayectoria del escritor español Juan José Millás (Valencia, 1946) el periodismo ocupa un lugar destacado. Lejos de ser un oficio circunstancial, este autor ha simultaneado la publicación de sus novelas con una extensa carrera en los medios de comunicación nacionales, convirtiéndose en articulista habitual del diario El País o reportero destacado del suplemento dominical El País Semanal. Todos estos trabajos presentan similitudes estructurales, lingüísticas y discursivas con su escritura ficción. No obstante, entre todas estas semejanzas que son posibles localizar, existe una que atraviesa a toda su producción y que sienta las bases de elementos tan significativos como la selección de personajes o el enfoque del relato: el tema de la identidad. Con el fin de hacer un estudio extenso sobre este tema y demostrar las conexiones que existen entre su literatura y su periodismo, este artículo propone un análisis cualitativo textual y semiótico de la obra de no-ficción Hay algo que no es como me dicen: el caso Nevenka Fernández contra la realidad, en la que Millás reflexiona acerca de la identidad del individuo y de los factores que intervienen en su construcción.

\section{Palabras clave:}

Identidad; Juan José Millás; Nevenka Fernández; no ficción; Periodismo Literario.
Received: 13/09/2021 - Accepted: 23/12/2021 - Early access: 28/12/2021 - Published: 01/01/2022 Abstract:

Journalism occupies an important place in the career of the Spanish writer Juan José Millás (Valencia, 1946). This author has combined the publication of his novels with an extensive career in the Spanish media and became a regular columnist for the newspaper El Pais and an essential reporter for the supplement El País Semanal. These journalistic texts have structural, linguistic, and discursive similarities with his fiction novels. However, among all the similarities, the theme of identity is the most significant. The theme of identity runs through all his works and lays the foundations for substantial elements such as selecting characters or the story's focus. This article proposes a qualitative textual and semiotic analysis of the non-fiction novel Hay algo que no es como me dicen: el caso Nevenka Fernández contra la realidad to make an extensive study on this topic and demonstrate the connections between his literature and his journalism, in which Millás reflects on identity and the factors involved in its construction.

\section{Keywords:}

Identity; Juan José Millás; Nevenka Fernández; nonfiction; Literary Journalism.

Cómo citar este artículo:

Fuentes Hernández, P. (2022). La construcción de la identidad en el periodismo literario de Juan José Millás: el caso Nevenka Fernández. Doxa Comunicación, 34, pp. 307-323.

https://doi.org/10.31921/doxacom.n34a1474 


\section{Introducción}

"Me cuesta mucho ver la frontera entre escritor y periodista. Sobre todo en los géneros en los que yo trabajo". Estas declaraciones, recogidas por la revista Jot Down en el año 2012, ponen de manifiesto la estrecha relación que existe entre la obra periodística y literaria de Juan José Millás ${ }^{1}$. Este autor se inserta así en la tradición del periodismo literario, “un macrogénero que, bajo otros géneros, agrupa un conjunto de textos que son al mismo tiempo periodismo y literatura” (Angulo y Rodríguez, 2010: 11). Estamos ante un fenómeno que, aunque parte del periodismo, se sirve de otras ramas como la literatura, la historiografía, la sociología o la documentación, con el objetivo de contar una historia a través de diferentes herramientas narrativas, sin renunciar a principios tales como la investigación o la veracidad (Cuartero, 2019).

La noción de periodismo literario es controvertida y entraña numerosas discusiones ${ }^{2}$. A pesar de ello, es posible encontrar espacios de consenso a la hora de enumerar determinadas características. Por ejemplo, al periodista literario se le asigna una actitud subjetiva, creativa y de rechazo a las estructuras prefijadas, lo que convierte a la inmersión, la voz, la exactitud y el simbolismo rasgos intrínsecos a estos trabajos (Fernández y López, 2013). Para Norman Sims, creador de la antología The Literary Journalists (1984), la esencia del periodismo literario reside en su interés por comprender la cultura y la naturaleza humana. La estética, por tanto, está al servicio de la información y no solo tiene la función de embellecer el relato, sino también de prestar atención "en los detalles que el periodismo tradicional y estandarizado ignora, alcanzando una dimensión más humana y, por tanto, más real de la historia" (Angulo y Rodríguez, 2010: 12).

No obstante, el elemento que más define a este tipo de prácticas es la mirada personal del escritor: "Es la voz de una persona desnuda [...] que habla por sí misma. Alguien que ha iluminado la experiencia con sus reflexiones propias, pero que no ha dejado de lado sus particularidades, su sarcasmo, sus dudas, y que no borra sus realidades emotivas de tristeza, alegría, emoción, furia, amor" (Kramer, 2001). Tal es así, que muchos investigadores van más allá y sostienen que el periodismo literario es "un género independiente que solo puede ser practicado por aquellos periodistas que se han formado directamente desde la poesía a la novela" (Gutiérrez, 2009: 46).

En España, el periodismo literario comienza a asentarse de la mano de Mariano José de Larra y los costumbristas; continuó desarrollándose con el periodismo de opinión y el ensayo de pensadores tales como Leopoldo Alas, Miguel de Unamuno, Azorín, Ramón Gómez de la Serna, o José Ortega y Gasset; y desembocó en el periodismo informativo y literario de Pedro Antonio de Alarcón, Wenceslao Fernández Flórez o Julio Camba (Chillón, 1993). En la actualidad destacan algunos nombres que se han

1 Estas no han sido las únicas declaraciones en las que Millás ha reflexionado sobre las relaciones intrínsecas que existen entre su periodismo y su literatura. El autor ha aprovechado numerosos eventos a lo largo de su trayectoria para dejar constancia de los transvases que se generan entre ambas áreas: “[...] con el periodismo he experimentado mucho y gran parte de esos experimentos los he llevado yo luego a mi literatura. Mi literatura sería muy distinta y sin duda peor sin mi periodismo. Y mi periodismo no tendría las virtudes que tiene si no fuera por mi literatura" (Cruz, 2016: 207). A pesar de estas interrelaciones, también ha señalado que es consciente de las barreras que existen entre una y otra disciplina: "[...] hay normas. Si trabajas en un medio donde el pacto que tienes con el lector es que lo que vas a contar ha sucedido, tienes que respetarlo" (Sarriá, 2019).

2 Desde la perspectiva de López Pan (2004: 223), aquellos que rechazan el periodismo literario lo hacen "restringiendo las nociones de periodismo y literatura, puesto que hay periodismo más allá del informativo y hay literatura más acá de lo artístico". Por su parte, Muñoz-Torres (2002) explica este rechazo por la asociación de la literatura con la estética y el periodismo con otros conceptos tales como objetividad, eficacia comunicativa o austeridad estilística. Tampoco existe un consenso en cuanto al nombre con el que denominar estas propuestas. Son numerosos los términos empleados para referirse a esta práctica periodística: periodismo reposado, crónica de largo formato, periodismo de libro, narrativa periodística, novela testimonio, ficción verdadera, literatura de no ficción, etcétera. (Fernández \& López, 2013). Tal es el nivel de disconformidad que es posible contabilizar más de treinta vocablos distintos (Cuartero, 2019). 
convertido en los herederos contemporáneos de esos autores, como es el caso Francisco Umbral, Manuel Vicent, Maruja Torres, Manuel Leguineche, Raúl del Pozo, Rosa Montero, o el objeto de estudio de este análisis, Juan José Millás.

Juan José Millás es un escritor español que ha compaginado su labor periodística con su actividad literaria. Cumpliendo con los preceptos que fundamentan a cada disciplina, ha logrado crear una cosmovisión particular en todos sus trabajos, con características comunes que van desde la estructura, a los personajes, los elementos espacio-temporales o las técnicas narrativas utilizadas. No obstante, si hay un aspecto que distingue el estilo de Millás del de otros escritores de su generación ese es el cuestionamiento de la identidad, un eje temático que atraviesa a toda su producción.

Este autor describe en sus obras su tensa coexistencia con su realidad, de la que no se siente parte y que, bajo su punto de vista, se fundamenta en apariencias, extravagancias y contradicciones. Para Millás, la realidad está basada en un modelo ortodoxo, que se asimila a través de instituciones como la familia, el aparato educativo o los medios de comunicación, y que se encarga de la significación de nociones como la normalidad, la extrañeza, lo lógico o lo absurdo (Ródenas, 2006). Sostiene, en consecuencia, que eso que llamamos realidad no es más que "un delirio consensuado" (Arenas, 2019). Esta percepción también la aplica a sus personajes, cuyas historias tienen como base su lucha contra el mundo y su propósito de configurar una nueva identidad, ajena a estos convencionalismos preestablecidos.

Esta investigación pretende analizar el tratamiento que recibe el tema de la identidad en su primera novela de no-ficción, Hay algo que no es como me dicen: El caso Nevenka Fernández contra la realidad, y las correlaciones que presentan las ideas que plantea ella con sus otros trabajos. De esta forma, se intentará demostrar cómo, a pesar de las diferencias que existen entre ambas disciplinas, la literatura y el periodismo de este autor son dos áreas que están interconectadas por un mismo pensamiento.

\section{Metodología}

El objetivo principal del presente artículo es abordar el tema de la identidad en la obra Hay algo que no es como me dicen: el caso Nevenka Fernández contra la realidad, escrita por Juan José Millás y publicada en 2004. Se sitúa, por tanto, en la línea de investigación encargada del estudio del mensaje periodístico, que analiza los rasgos lingüísticos y literarios de los discursos informativos en paralelo a otras características de significación política, cultural o sociológica (Casals, 2005).

Particularmente, nos adherimos a la idea que defienden algunos teóricos, como Albert Chillón o Gérard Genette, y que sostiene que una obra periodística puede ser estudiada como un producto literario. Genette, por ejemplo, plantea en su libro Ficción y dicción (1991) que la literariedad, que normalmente ha estado asociada con el contenido de un texto, también puede provenir de su forma, lo que permite que otro tipo de trabajos narrativos puedan ser considerados como literatura.

Se ha seleccionado Hay algo que no es como me dicen de entre todas las publicaciones de Millás al tratarse de su primera novela de no-ficción, es decir, de un trabajo híbrido entre su periodismo y su literatura, que puede proporcionar información sobre las semejanzas que existen entre ambas disciplinas. Esta publicación se basa, por un lado, en un hecho real: el denominado "caso Nevenka", cuya resolución supuso la primera condena por acoso sexual a un político en España. Por otro, emplea recursos propios de su ficción y motivos que son recurrentes en las tramas de sus novelas. 
En el estudio del mensaje periodístico, muchos autores defienden el uso de las herramientas cualitativas, debido a que focalizan en aspectos como el lenguaje, la narrativa, el estilo o la retórica de los mensajes ${ }^{3}$. En paralelo a esta idea, se ha considerado que el cualitativo es el modo de investigación más apropiado para este análisis, ya que conecta directamente con la finalidad de nuestro estudio. En concreto, se ha optado por un análisis cualitativo textual y semiótico de la tradición crítica literaria, desarrollado por el New Criticism de la escuela angloamericana y su homóloga francesa, con el método de la explication du texte.

Además, se han empleado como categorías de análisis dos conceptos clave en las obras de Millás, "identidad” y “extrañamiento", que explican su acercamiento y representación de la realidad que investiga y relata. Para hablar de identidad, se ha seguido la definición establecida por la corriente psicoanalítica, ya que es la que contempla el autor a la hora de componer sus escritos. El psicoanálisis asocia la formación del yo con un sistema de creencias que funciona como sostén imaginario de "sí mismo" y que tiene poco que ver con la verdad del sujeto (Elgarte, 2011). Millás ve la identidad bajo este prisma, considerándola una construcción pactada que se socializa y aprende y que con sus historias pretende confrontar. En cuanto a la noción de extrañamiento, se ha tenido en cuenta como principal referencia el ensayo de Gonzalo Sobejano “Juan José Millás, fabulador de la extrañeza" (2007). El extrañamiento hace alusión al "efecto enajenador del mundo descrito sobre la conciencia que vive o describe ese mundo" (Sobejano, 2007: 501) y vincula a todos los personajes principales de sus obras, que impulsados por una angustia existencial deciden rehuir de su identidad y crear una nueva, que tiene como base sus fantasías (Knickerbocker, 2007).

Por último, los resultados obtenidos se han ido ampliando a través de una revisión bibliográfica exhaustiva de otras fuentes primarias de información, que han provenido fundamentalmente de investigaciones dedicadas al estudio de los textos de Juan José Millás. Durante estos análisis comparativos nos hemos centrado, sobre todo, en los temas, argumentos y motivos comunes, es decir, en "las conexiones intra e interliterarias de materias, temas, topoi y loci, figuras, símbolos, tipos, emblemas alegorías, motivos, etcétera” (Chillón, 1999: 407).

Con todo, pretendemos establecer los enlaces que existen entre la literatura y el periodismo de Millás y aportar más información al perfil de este autor. A su vez, buscamos desarrollar nuevas aportaciones en los estudios dedicados a examinar las interacciones que se dan entre estos dos campos y demostrar que, a pesar de sus diferencias, son dos disciplinas que están vinculadas entre sí.

\section{Resultados: Análisis de la obra Hay algo que no es como me dicen: el caso Nevenka Fernández contra la realidad}

\subsection{La identidad como eje fundamental del pensamiento millasiano}

Juan José Millás nace en Valencia en 1946. Comienza a adquirir popularidad en el panorama literario tras obtener el Premio Sésamo por su segunda novela Cerbero son las sombras (1975). Desde entonces, su obra ha sido traducida a veintitrés idiomas distintos y ha recibido numerosos reconocimientos, tales como el Premio Nadal, el Premio Planeta o el Premio Nacional de Narrativa, que le han convertido en uno de los escritores más reconocidos de la España actual.

3 “El estudio del periodismo como saber y como transmisión docente de dicho saber deberá centrarse en el estudio de todas las formas de mensaje que su actividad pueda generar y cómo se adapta el mensaje a los diferentes medios comunicativos. [...] Importa mucho más qué se dice y las posibilidades de cómo decirlo a cuántas veces se dice de determinada forma" (Casals, 2005: 245). 
Desde sus inicios, Millás ha compaginado su actividad literaria con su labor periodística, trabajando en múltiples formatos para medios de comunicación nacionales. En radio ha colaborado con Cadena SER en programas como La Ventana o A vivir que son dos días. En prensa escrita es principalmente conocido por sus columnas de opinión, aunque también destaca por su labor como reportero en El País Semanal. Como él mismo reconoce, son dos ámbitos que, en su caso, no pueden ser estudiados por separado: su periodismo se ha visto enriquecido por su estilo literario y, a su vez, muchos de los cambios que ha ido experimentando su narrativa han comenzado efectuándose en sus textos publicados en prensa. De ahí nace Articuentos, un género creado por él mismo que proviene de la hibridación entre el cuento y la columna de opinión: “[...] son textos refractarios a la clasificación, encabalgados entre el comentario de actualidad y el relato, entre la referencialidad y la autorreferencialidad, entre lo factual y lo ficcional" (Ródenas, 2006: 60).

No obstante, de entre todos los enlaces que permiten establecer una línea de continuidad entre la literatura y el periodismo de Millás destaca un tema especialmente significativo: el cuestionamiento de la identidad y, en concreto, en el sentimiento de no pertenencia de sus protagonistas hacia el mundo que les rodea. Como indica Anastasio (2009), cualquier lector familiarizado con los textos de este autor es capaz de reconocer este sello de su escritura. Incluso, ha sido él mismo quien lo ha identificado como un eje temático elemental que atraviesa a toda su producción: "A mí me ha tocado como problema fundamental el de la identidad y creo que tiene que ver con esa preocupación que mantengo en toda mi obra por distinguir entre la apariencia y la realidad de las cosas" (Gie Koh, 2011: 239).

Para Millás, eso que llamamos realidad "es una construcción delirante sobre la que hemos llegado al acuerdo" (Iglesia, 2017) y de la que, por el momento, no existe alternativa. Esta concepción del mundo es interesada y ha sido creada y difundida por instituciones como la familia, la política, la religión, la escuela o los medios de comunicación, que además de regir nuestro comportamiento, valores o ideas, dotan de significado a conceptos tan relevantes para la organización del tejido social, como la normalidad, la lógica o la locura (Ródenas, 2006). Millás confronta estas convenciones mediante los personajes de sus novelas, columnas y reportajes, que no terminan de comprender del todo las bases de este pacto preexistente. Esta situación les provoca una crisis de identidad que les impulsa a iniciar un viaje para descubrir su verdadera esencia, ajena a imposiciones y apariencias.

En ese sentido, uno de los términos que más se han empleado a la hora de caracterizar a los protagonistas de sus obras es el de la acomodación: "El individuo se convierte en un autómata: una apariencia de individuo manejado o conducido realmente por una instancia superior cuyos fines permanecen ocultos al obediente muñeco" (Sobejano, 1992: 320). Anastasio (2009) pone como ejemplo de ello a Vicente Holgado, que confecciona su identidad mediante la reproducción de gestos aprendidos de otros, o a Olegario, personaje de Tonto, muerto, bastardo e invisible (1995), que disimula su condición de tonto a través de la imitación. Muchos de estos protagonistas "acomodados", en el momento en el que se dan cuenta de que las apariencias son las que han construido su personalidad, inician un proceso denominado "extrañamiento", con el que comienzan a desprenderse de lo conocido y a romper con esos "elementos que, disfrazados de realidad, acaso impiden alcanzar lo real" (Bértolo, 1983: 213).

El extrañamiento describe el modo de observación que emplea el autor para analizar lo familiar desde una posición crítica. Se trata de un procedimiento que hereda de la tradición literaria y que le sirve para representar aquellas cosas a las que estamos habituados de un modo insólito (Lodge, 1998). El extrañamiento puede ser practicado desde el punto de vista conceptual o mediante el empleo de palabras o fórmulas estilísticas poco habituales, como la exageración o la parodia: 
¿Qué queremos decir cuando afirmamos -y es un elogio muy común- que un libro es original? no queremos decir con ello, en general, que el escritor ha inventado algo sin precedentes, sino que nos ha hecho percibir algo que en un sentido conceptual, [...] lo ha hecho desviándose de los modos convencionales, habituales, de representar la realidad. Desfamiliarización, es una palabra, es otra manera de decir originalidad (Lodge, 1998: 91).

La extrañeza es el enfoque con el que el autor construye algunas de sus obras más celebradas. Para Ródenas (2006), esta visión se manifiesta en novelas como El desorden de tu nombre (1987), La soledad era esto (1990), Tonto, muerto, bastardo e invisible (1995), El orden alfabético (1998), No mires debajo de la cama (1999) o Dos mujeres en Praga (2002).

También, esta perspectiva está presente en sus textos periodísticos, cuya temática principal se basa en este cuestionamiento de lo dado, lo tangible y lo azaroso (Rojas, 2018). Por un lado, en su columnismo efectúa un "acceso crítico al funcionamiento del mundo" (Ródenas, 2006: 64) que le permite tomar distancia para hablar sobre los errores de ciertos sistemas o fórmulas sociales:

Millás no se limita en sus columnas a expresar su punto de vista sobre un hecho de actualidad, sino que previamente transforma ese hecho en un fenómeno insólito, lo enajena como si perteneciera a una esfera de experiencia extraña a él y al lector [...] Millás pone en cuestión tanto las leyes naturales (estas de manera metafórica) como las convencionales, lo que le permite presentar en sus columnas el acontecer de la actualidad como el producto del caos, el azar o el acuerdo interesado (Ródenas, 2006: 62-63).

En sus columnas, Millás consigue llevar a cabo productos híbridos que aúnan los elementos informativos con su universo de motivos y obsesiones (Ródenas, 2006). De este modo, la identidad también pasa a convertirse en el eje central de estos textos:

Si en sus novelas la soledad, la identidad individual, las relaciones de la persona con sus orígenes, la memoria, la muerte, los espacios, los límites... son temas reiterados, en sus columnas se traducen en reflexión sobre la incomunicación, la enfermedad, los límites de la democracia, los sorprendentes avances de la biomedicina y sus posibilidades, la tecnología y su irrupción en nuestras vidas, o la marginación de los individuos en una sociedad ajena a las necesidades de los más vulnerables (Marín, 2011: 313).

Por otro, se sitúa su reporterismo, donde esta epistemología del extrañamiento queda aún más patente. Desde que comienza a trabajar para el suplemento dominical El País Semanal existe una tendencia a escribir textos cuyo propósito principal sea el desmantelamiento de juicios y expectativas previas que, aunque falsas, están asentadas en la sociedad. El claro ejemplo reside en su primera serie de reportajes, Proyecto sombra (2001-2006), constituida por dieciséis entregas que describen el día a día de diversos personajes, los cuales, y a pesar de sus diferencias, están seleccionados bajo un mismo criterio: individuos cuyas vidas están obstaculizadas por un estigma. Algunos de sus protagonistas son conocidos por los lectores y se adscriben a ámbitos como la cultura, la política o el deporte. El reportero desarrolla un análisis de su imagen pública, que suele estar basada en tópicos o juicios subjetivos que difieren bastante de sus verdaderos rasgos. Otros, en cambio, a pesar de ser desconocidos, son relevantes por sus circunstancias sociales, culturales o económicas. En estos casos, Millás investiga sobre los estereotipos bajo los que se ven afectados e intenta abrir una brecha que promueva un cambio de mentalidad:

Sí, es el punto de arranque de estos reportajes y en general de la literatura. En el origen de un texto literario siempre hay un conflicto, algo que tiene que ver con una falta de entendimiento de la realidad y de la propia realidad, de familiarización con lo que para la mayoría de la gente es familiar. Lo que uno busca siempre que escribe, sea un texto de ficción o un reportaje, es intentar ordenar la realidad, que es un modo de intentar entenderla (Montes, 2012). 
Con todo, sus relatos se constituyen como "la constatación de que existe una realidad distinta a la versión mostrenca que a veces presenciamos" (Anastasio, 2009: 219). Con sus historias, desarrolla "una relectura crítica de la experiencia colectiva a través del impacto que tiene sobre el desenvolvimiento personal de los individuos" (Tanner, 2016: 16). Para ello, apela directamente a los lectores, invitándoles a apropiarse de la experiencia de sus personajes y a crear una nueva interpretación de su realidad más cercana.

Juan José Millás compagina la elaboración del Proyecto sombra con la publicación de su primera novela de no-ficción. En Hay algo que no es como me dicen, este autor toma un suceso de abuso sexual y lo utiliza para reflexionar acerca de la identidad y la no pertenencia. El autor plasma cómo la sociedad está dispuesta a intentar silenciar la voz de una víctima con tal de mantener la estructura social hegemónica en la que viven. Por el contrario, Nevenka, a pesar del rechazo que provoca su testimonio, decide romper con el imaginario que imperaba sobre las mujeres en aquella época y, en consecuencia, construir una nueva identidad distanciada de esas ideas previas.

\subsection{Hay algo que no es como me dicen: una obra entre la literatura y el periodismo}

Hay algo que no es como me dicen: el caso Nevenka Fernández contra realidad se presenta como un reportaje novelado que reconstruye los acontecimientos del denominado "caso Nevenka", que nace de la denuncia pública por acoso sexual de la concejala de Hacienda y Comercio del Ayuntamiento de Ponferrada, Nevenka Fernández, a su jefe y alcalde de la ciudad, Ismael Álvarez. Este evento de la actualidad social española ocupó durante el año 2001 las portadas de los principales periódicos nacionales y se convirtió en el tema central de las tertulias televisivas.

El libro, que va alternando el presente de la escritura con el pasado de la protagonista, también relata la investigación periodística que desarrolla el autor entre 2001 y 2003 para desentrañar los entresijos de este caso. A lo largo de la lectura, y mediante un narrador homónimo en primera persona, Millás aporta documentación, detalles específicos de sus encuentros con Nevenka y descripciones sobre los obstáculos a los que se tuvo que enfrentar durante la elaboración de este extenso reportaje. Se genera así una especie de "metarreportaje", en el que no solo se examinan los elementos, causas y consecuencias de estos hechos, sino en el que también se realiza una reflexión de su labor como periodista:

Nevenka y yo nos sentábamos a una mesa camilla de aquel salón cada lunes o cada jueves, según el día que hubiéramos quedado, yo encendía el magnetofón, sacaba los cuadernos de notas y comenzábamos a hablar. Como es lógico, hablaba fundamentalmente ella. Yo me limitaba a provocarla para que se explayara, le ponía zancadillas, la colocaba frente a contradicciones [...] (Millás, 2004: 40).

De entre todos los datos que aporta acerca de su trabajo, el autor revela qué suscitó su interés en este suceso. Nevenka Fernández es un personaje de la realidad social española que responde a las características del universo millasiano, pues la concejala, al denunciar públicamente su situación, rechaza las convenciones sociales impuestas por su entorno, que le forzaban a cumplir con un rol de género basado en la docilidad y la discreción": "Añadí que me había llamado la atención el modo en que esa mujer

4 Previo a esta obra, el autor ya se había interesado por este hecho, dedicándole una columna titulada "Nevenka", que publicó en El País el 6 junio del 2002. Casi veinte años después, el 5 de marzo de 2021, Netflix estrenaba Nevenka, una docuserie dirigida por Maribel Sánchez-Maroto en la que también participaba Millás, relatando su experiencia de escritura y la evolución que observó en la protagonista tras los múltiples encuentros que concertaron durante ese tiempo. En todos estos formatos, siempre ha recalcado las causas que le llevaron a investigar este suceso, que responden a los temas centrales de su universo narrativo: “[...] lo 
se había autoexcluido del grupo social y cultural al que pertenecía sin tener otro recambio" (Millás, 2004: 32). Nos encontramos, por tanto, con una obra que reflexiona acerca de la identidad, en la que el foco no reside tanto en las escenas de acoso, sino en el proceso de evolución de la protagonista, cuya personalidad parte de una serie de prejuicios previos que van a ir deconstruyéndose hasta alcanzar un nuevo relato personal: “[...] Al denunciar el caso, había renunciado a su identidad sin tener otra de repuesto” (Millás, 2004: 25).

Millás traza una línea de continuidad entre Nevenka y las protagonistas de sus novelas: "A veces la vida produce novelas de manera espontánea y a mí me pareció que aquí había una novela [...] tenía, por decirlo en nuestro argot, el sentimiento de que ahí había "una historia» y yo quería contarla" (Millás, 2004: 28). Incluso, establece conexiones entre personajes literarios concretos y los rasgos de la personalidad de la concejala, a la que le atribuye la etiqueta de "novelesca" (Millás, 2004: 37). La enlaza, de esta forma, con el personaje principal de La soledad era esto, una fumadora que atraviesa una crisis de identidad que se solventa "cuando averigua lo que representa el hachís y deja de fumar", o con una de las protagonistas de Dos mujeres en Praga, que como Nevenka decide relatar su vida al escritor (Millás, 2004: 40).

En ese sentido, Hay algo que no es como me dicen se acerca a su literatura, ya que tanto por su contenido, como por su estructura o su manera de narrar presenta todos los elementos característicos de su ficción. Lo vemos, por ejemplo, en el inicio de narración, que Millás aborda como si de un cuento se tratase: "Esta es la historia de una mujer sensata que cuando se dio cuenta de que todo lo que le habían contado era mentira, fue al juzgado, denunció los hechos y lo puso todo patas arriba” (Millás, 2004: 9). Lo mismo ocurre en el desenlace de la historia, que compara con el final de la fábula clásica Hansel y Gretel:

[...] si me preguntan por qué valió la pena escribir este libro, diría que porque al fin he logrado averiguar el final de Hansel y Gretel, un cuento que me obsesiona desde la infancia y que tuve que leer en una edición a la que alguien había arrancado las últimas páginas. Y no termina ni bien ni mal, termina regular, como casi todo en esta vida (Millás, 2004: 202-203).

No obstante, por la investigación y la veracidad que basan a este texto, también se aproxima a sus textos periodísticos. Nos encontramos, así, con un producto híbrido entre estas dos disciplinas en el que pueden observarse las características más relevantes de su estilo de escritura y en el que la identidad adquiere un papel crucial para la trama del relato:

[...] Nevenka y yo, que estábamos el uno junto al otro, nos encontramos momentáneamente aislados en el interior de aquel grupo de cuatro. Entonces me preguntó porque quería contar su historia y me remití a los argumentos que ya había dado en la columna “Nevenka” publicada en El País (el extrañamiento respecto a los suyos y quizá también respecto a sí misma), pero finalmente añadí que no lo sabía a ciencia cierta y que esperaba averiguarlo a medida que escribiera. Seguramente, dije también, que ese era, por otra parte, mi modo de trabajar, tanto cuando hacía periodismo como cuando hacía literatura, en el caso de que el periodismo y la literatura fueran cosas diferentes (Millás, 2004: 36).

interesante aquí es el proceso de extrañamiento de la acosada, de la víctima. 'Habla con él', le decían ingenuamente sus padres, reacios a creer que un individuo que defendía el mismo orden en el que ellos creían fuera un canalla" (Millás, 2002). 


\subsection{Romper con lo estipulado: hacia una nueva interpretación de la realidad}

La realidad que se dibuja en Hay algo que no es como me dicen está fragmentada en dos planos que rememoran en cierta medida la alegoría de la caverna platónica ${ }^{5}$. El primero de esos planos está basado la realidad convencional. Se trata de un espacio compuesto de normas y comportamientos preestablecidos, es decir, de sombras y apariencias, en donde la identidad se configura a través de la imitación y la asimilación de estas pautas. En contraposición a este mundo, existe un plano alternativo, constituido por planteamientos ajenos a estos convencionalismos, al que es posible acceder tras un proceso paulatino y complejo, que termina con la obtención de un nuevo relato personal.

El tránsito de una esfera a otra no es sencillo: las personas que estén dispuestas a vivir esta transformación sufrirán la exclusión social, con consecuencias que, como indica el autor, varían según la época o el asunto: "puede ir desde la cárcel a la horca, pasando por la multa, el exilio, el aislamiento, el escarnio público o el desarraigo [...]" (Millás, 2021). Esto se explícita en la historia de Nevenka, cuya denuncia provoca una profunda grieta entre ella y su entorno: "No se soportaba que la víctima abandonará su papel de víctima porque eso descolocaba todo en las cabezas y en la realidad” (Millás, 2004: 19).

La dicotomía que establece Millás entre uno y otro plano se reproduce a lo largo de la lectura y afecta a todos sus personajes, que deben decidir en qué lugar se posicionan, si a favor o en contra de la protagonista: "Es verdad que sus padres, una vez formalizada la denuncia, se pusieron incondicionalmente de su parte, pero ahora todavía vivían en el otro lado de la realidad” (Millás, 2004: 82). Muchos de los que seleccionan la esfera de lo convencional no estaban interesados en descubrir la verdad, sino en las consecuencias que podría acarrear la experiencia de Nevenka para la organización social, adoptando una postura de acomodación y automatismo. Otros, en cambio, decidirán iniciar su transición junto a ella, intentando demostrar en la medida de lo posible la veracidad de su testimonio.

Esta dualidad también se extenderá al juego retórico que se establece entre términos opuestos como la prudencia y la insensatez, el delirio y la cordura o la lógica y la irracionalidad, que le sirven al escritor para cuestionar los marcos normativos vigentes. Por ejemplo, mientras que para muchos lo sensato "era dimitir y olvidarse del asunto" (Millás, 2004: 94), para Nevenka este tipo de sensatez atentaba contra su dignidad, prefiriendo acogerse a la imprudencia que a la mesura: "Nevenka dijo hasta aquí hemos llegado, no seré sensata nunca más, y entonces fue al juzgado, denunció los hechos y lo puso todo patas arriba” (Millás, 2004: 116).

No obstante, la actitud de la protagonista no es homogénea, sino que experimentará una serie de variaciones a medida que se van sucediendo los acontecimientos. Debemos tener en cuenta que el acoso de Álvarez comienza con actos sutiles que la concejala llega a naturalizar: "Ismael Álvarez llamaba, por ejemplo, a Nevenka para despachar un asunto de trabajo y al terminar la reunión, decía: «Bueno, vamos a tomar un café». ¿Quién se negaría a tomar café con un superior sin ser calificado de loco?” (Millás, 2004: 158-159). Sin embargo, este comportamiento se va haciendo cada vez más repetitivo y perceptible con el paso del tiempo,

5 La relación que existe entre los textos de Millás y el mito platónico de la caverna ha sido examinada por otros autores. Encontramos, por ejemplo, la investigación que realiza Carter Smith titulada "Like Prisoners in a Cave: A Problematic Search for Identity and Truth in Two Peninsular Novels" (2012), en la que se desarrolla un estudio de la obra de ficción El orden alfabético (1998). También, se localizan los trabajos que elabora Teresa González Arce, como "Periodismo, ficción y realidad: a propósito de Todo son preguntas, El ojo de la cerradura y Sombras sobre sombras de Juan José Millás” (2008: 91-92), en el que aborda un análisis sobre estas tres recopilaciones de artículos del autor: "Platón decía, como sabemos, que el mundo era una gran caverna en la cual se proyectaban las sombras de las formas sensibles que existían en el exterior. Para Millás, no sólo el universo funciona así, sino también todos y cada uno de sus habitantes: “Comprendí”, leemos en el prólogo a Sombras sobre sombras, "que no otra cosa somos cada uno de nosotros: cámaras oscuras en las que penetran las imágenes del mundo, atrapado a su vez en una cámara oscura mayor" [...]". 
y la concejala irá tomando consciencia de la gravedad de la situación. Aun así, el rol pasivo que ha asimilado le lleva a mantener el silencio durante meses, hasta que, finalmente, emprenderá un proceso en dónde cuestionará el papel que hasta entonces se había visto obligada a cumplir.: "[...] la doctora le preguntó si había oído hablar de una cosa llamada acoso sexual y a Nevenka le pareció que eso solo ocurría en las películas, y ni siquiera en las películas serias, sino en los culebrones. Ella no podía estar siendo víctima de un culebrón" (Millás, 2004: 55).

Es ahí cuando comienza el hostigamiento por parte de los individuos adscritos al primer plano de la realidad para conservar su hegemonía. Primeramente, la protagonista sufrirá las consecuencias del propio Ismael Álvarez, su acosador, que intentará perpetuar su poder mediante diferentes acciones de control: "A medida que se iba liberando de las ataduras emocionales del pasado, aumentaba también el número de llamadas amenazantes que intentan hacerla regresar al estado de sumisión anterior" (Millás, 2004: 129-130). Su actitud también será penalizada por parte de su entorno, que preferirán mantener el discurso conocido a adentrarse en el universo desconocido y rupturista que defiende Nevenka: "Fue en el interior de esa atmósfera donde la voz de Nevenka adquirió, pese a su fragilidad, un valor inexplicable, como si cada vez que pronunciará una palabra se quebrara un cristal" (Millás, 2004: 13).

En concreto, son dos las respuestas mayoritarias que recibe la protagonista. En primer lugar, la indiferencia. Determinados personajes preferirán ignorar su situación antes de aceptar las incoherencias de su mundo: “— ¿Tú sabes lo que has hecho? — ¿Pero tú sabes lo que él me ha hecho a mí? —respondió perpleja Nevenka. — ¡Yo no sé nada, no sé nada! ¡Nada!” (Millás, 2004: 18). Otros, en cambio, manipularán la realidad con tal de ponerla a su favor. Lo vemos, por ejemplo, con las declaraciones de muchos testigos, que sostenían que la concejala "estaba hablando demasiado" (Millás, 2004: 26), a pesar de que apenas concedió entrevistas a los medios.

No obstante, el argumento más repetido para inhabilitar su voluntad es el del delirio. Teniendo en cuenta que para la sociedad Álvarez "representaba la normalidad" (Millás, 2004: 28), Nevenka quedaba fuera de esa noción que definía a lo ordinario, lo que provocaba que toda palabra que pronunciase, fuese invalidada por enfermedad o locura. Aun así, se mantuvo en su posición, pues estaba en el convencimiento de que "nada era como le habían dicho. Todo era un atajo de mentiras a cuya construcción ella misma había contribuido hasta que dijo no" (Millás, 2004: 117).

\subsection{El delirio de Nevenka}

En los universos narrativos de Millás "predominan las anomalías, las rupturas y transgresiones de la versión oficial de la realidad, protagonizadas por seres que no ven ni entienden lo que supuestamente deberían ver y entender" (Ródenas, 2016). Se trata de un delirio que experimentan sus personajes y que le sirve al autor para criticar las connotaciones que entraña la noción normalidad, que ha sido utilizada para delimitar comportamientos, corporalidades o circunstancias. Aquello que responde a estos límites establecidos es aceptado y validado por la sociedad, mientras que lo que se sale de este marco es etiquetado de raro, desviado o ambiguo. Esta condena de la diferencia provoca que los seres humanos, en vez de distinguirse de sus semejantes, intenten parecerse a ellos, asimilando de manera inconsciente una serie de patrones de comportamiento.

Por el contrario, Millás defiende en sus textos la idea de diversidad. Para ello, da voz a protagonistas disidentes como Nevenka, cuyo testimonio trastoca la arquitectura del mundo al que había pertenecido. Esto genera un sentimiento de incomprensión 
general que impulsa a muchos individuos de su entorno a buscar diferentes argumentos que desarticulen su discurso y que la induzcan a volver al punto de partida. Entre ellos, vuelve a destacar el argumento del delirio.

Uno de los personajes que más emplea el término "loca" para dirigirse a Nevenka es el propio Ismael Álvarez. El concejal de Ponferrada hace uso de la locura como excusa cuando siente una pérdida en su dominio. Para aplacar a su víctima, intenta alterar su percepción del entorno, consiguiendo que no se percate de su situación de acoso y, por ende, que no intente escapar de su control. Se trata de un ejercicio constante pero sutil que practica a lo largo de todo el texto y que acaba generando confusión en la joven: "Ismael Álvarez la llamó de todo. Le dijo que estaba loca ("tú no estás bien de la cabeza Quenka" era una de sus frases favoritas), se lo había dicho tantas veces que la propia Nevenka había llegado a pensar que no estaba en sus cabales” (Millás, 2004: 51).

Otros personajes, incluso miembros de su familia, también emplean la coartada del delirio para justificar las decisiones de la protagonista. En concreto, son tres las causas que se le asignan a Nevenka para esclarecer su aislamiento de la realidad en favor de una nueva interpretación del mundo: las drogas, su entrada en una secta y los problemas de alimentación. Todas ellas derivan a su vez de un mismo hecho: la enajenación mental.

Se dio cuenta, por si fuera poco, de que creían realmente que era una drogadicta. Anoréxica, loca y drogadicta: el chivo expiatorio perfecto para usarla de cubo de basura. Podían colocar en ella todo lo que detestaban de sí mismos y continuar más o menos felices en aquel mundo perfecto (Millás, 2004: 82).

No obstante, tal y como indica el narrador, las drogas, y en particular los ansiolíticos y antidepresivos, los problemas de alimentación o los comportamientos extraños son el resultado de la situación de acoso continuado que padece, y no la causa como algunos pretenden sostener. Nevenka, por ejemplo, emplea los tranquilizantes como vía de escape, pues aceptar su posición de víctima, sumada a la exclusión social a la que es sometida, son circunstancias difíciles de asimilar. Sus esfuerzos, más que en comprender el porqué de su situación, se dirigen en un principio y mediante estos métodos "a no pensar, porque cuando pensaba como había llegado aquella situación se volvía loca" (Millás, 2004: 76). Por estas razones, llega a admitir el relato de su locura: "Si me dicen que estoy loca -pensaba Nevenka-, les pediré que me encierren, que me mediquen y así cesará la pesadilla" (Millás, 2004: 52).

Nevenka solo acepta su posición de víctima y, con ello, su cordura cuando se le asigna un término al problema que experimenta: "acoso sexual". Es su psiquiatra quien le diagnostica un cuadro de ansiedad como consecuencia de esta situación personal y le confirma la coherencia y la validez de su testimonio. El informe de la psiquiatra se convierte, así, en "su documento de identidad" (Millás, 2004: 66), que le impulsa en su evolución y en dejar atrás todas las ideas, comportamientos y opiniones adscritas a su pasado.

De esta forma, se introduce otro de los temas primordiales de la escritura de Millás: el poder de la palabra a la hora de modificar nuestra percepción. Tanto en Hay algo que no es como me dicen, como en otros de sus trabajos literarios y periodísticos, el autor reflexiona sobre la capacidad que poseen las palabras para perpetuar los sistemas de poder, a la vez que pueden manifestar otras representaciones de la realidad que, por el contrario, desafíen ese régimen de creencias predeterminado.

Un ejemplo de ello se sitúa con La mujer loca (2014), una novela que está protagonizada por Julia, que no es capaz de percibir de manera ordinaria el lenguaje. Para ella, tal y como está establecido "no es una herramienta a nuestro servicio, sino un tirano que 
nos coarta" (Ródenas, 2016). Las reflexiones de este personaje presentan gran coherencia y acierto. Sin embargo, se salen de la normatividad impuesta. De ahí también deriva la etiqueta de "loca" que recibe la protagonista desde el título de la publicación.

En el caso de Nevenka se observa con el término acoso. Mientras en épocas anteriores la joven lo había rechazado por asociarlo con "mujeres incapaces de defenderse", ahora lo reconoce como suyo, ya que responde fielmente a la descripción de su experiencia (Millás, 2004: 89). Esta resignificación es debida a la lectura de libros, como Acoso Moral de Marie-France Hirigoyen; a las conversaciones con otras mujeres, como la que mantiene con su rival político Charo Velasco; o al diagnóstico de su psiquiatra Alfonso Hurtado. Se genera, así, un reconocimiento en las palabras y sus significados que le empujan a continuar con su proceso de extrañamiento, con el que lo conocido empieza a verse como raro, y lo extraño, como natural: "Nevenka Fernández comienza a modificar su relación con las palabras, que se ordenan ahora de una manera novedosa, formando en su conciencia constelaciones que alumbran un universo nuevo" (Millás, 2004: 128).

\subsection{El extrañamiento como desenlace de Hay algo que no es como me dicen}

El extrañamiento es un proceso artístico y literario que consiste en transformar lo familiar en ajeno y que configura las bases de la escritura de Millás. Para este autor, conseguir que el lector adquiera una visión alternativa de su mundo es uno de los propósitos principales de su narrativa, tanto periodística como literaria. Esto hace que se puedan establecer diferentes interconexiones entre sus trabajos a través del contenido de sus textos:

[...] Se trata de ver lo cotidiano para así iluminarlo de tal manera que eso que nos resulta familiar se convierta en extraño. Yo creo que una de las obligaciones de la literatura es desfamiliarizarnos de aquello que nos es familiar, porque es precisamente así que los hechos banales adquieren significado (Iglesia, 2017).

El extrañamiento también se convierte en la trama principal de Hay algo que no es como me dicen. El foco de esta novela de no-ficción reside en la historia de un personaje para quien lo ordinario ha perdido su sentido. Nevenka, mediante su experiencia, desarticula los roles de género que hasta entonces habían sido su referencia y las enseñanzas que había heredado de su entorno familiar. Este es el motivo por el cual el propio autor define su relato como "la historia de un extrañamiento" (Millás, 2004: 25):

Por ejemplo, su padre siempre se había referido peyorativamente a los homosexuales, pero Nevenka tuvo durante su época de estudiante en Madrid un amigo homosexual que era una persona encantadora, solidaria, justa. Por ejemplo, en su casa siempre había oído decir que quien se fumaba un porro es un drogadicto sin remedio, pero ella veía que sus compañeros de facultad fumaban porros sin dejar por eso de estudiar, de ir a misa y de atender a todas sus obligaciones. Por ejemplo, se había educado en la idea de que una mujer que se acostaba con dos hombres distintos era una ninfómana y tenía compañeras normales que habían pasado por esta experiencia sin acabar en un burdel (Millás, 2004: 117).

El extrañamiento se observa, por ejemplo, en la relación que establece la protagonista con sus padres desde el momento en que decide contarles su situación hasta que se formaliza la denuncia. Cuando estos son conscientes del acoso que padece su hija, prefieren rechazar su discurso antes de aceptar las bases del mundo en el que viven. Se genera de esta forma un contraste entre ellos y Nevenka, que habitan en dos esferas de la realidad distintas es donde prácticamente es imposible la comunicación:

a) [...] la extrañeza que sentía respecto a la casa se trasladó también a sus padres. No entendían nada, no se daban cuenta que si salía del Ayuntamiento de ese modo, no tendría a dónde ir [...] comprendió que estaba sola, completamente sola, y que ella tampoco 
era capaz de explicar cómo había llegado aquella situación, porque había sido un proceso lleno de sutilezas, repleto de actos cuya verdadera dimensión no se comprendía si no estaban debidamente articulados y ella era incapaz de articularlos en aquel momento, en la cocina de aquella casa extraña, en presencia de aquellos padres que le empezaban a parecer extraños (Millás, 2004: 67).

b) Con sus padres ya prácticamente ni hablaba. Se habían cortado los hilos de la comunicación. Ellos habían hecho un diagnóstico que ponía a salvo su mundo, aunque condenaba a su hija, y vivían instalados en el convencimiento de que Nevenka se había vuelto loca, cuando era evidente que quien se estaba loco era el mundo real. Nevenka había pertenecido a ese mundo loco del que ahora se iba alejando, del que iba cayendo sin tener otro mundo que la cogiera (Millás, 2004: 77).

Tal es la importancia del extrañamiento que Millás dedica un capítulo completo a analizar este fenómeno en profundidad. Se trata de "Fechas que no cuadran", que se corresponde con el undécimo episodio de este libro. En él, el autor desarrolla una revisión de diferentes eventos de la vida de Nevenka con el propósito de descubrir en qué punto de su biografía comienza este extrañamiento. Se comprueba entonces que fueron varios los acontecimientos en los que la protagonista se sintió ajena a su realidad. Previo al propio Ismael, se descubre que desde su fecha de nacimiento todo lo que le han contado sobre sí misma y sus orígenes no es verdad:

Nevenka tiene 15 años [...] ha encontrado una caja con fotografías familiares que se entretiene en ver para matar el tiempo [...] comprueba con asombro que las fechas de la boda de sus padres y la de su nacimiento no cuadran. Según el libro, ella había nacido a los dos meses de la boda, asunto incomprensible y seguramente escandaloso en la Ponferrada de los años 70, cuyas costumbres no habían evolucionado al mismo ritmo que en el resto del país (Millás, 2004: 109).

Nevenka, por lo tanto, "había nacido fuera de plazo" (Millás, 2004: 109), es decir, había desafiado desde su nacimiento a las leyes morales de la Ponferrada de aquel tiempo. Esta fue, en palabras del autor, la mentira inaugural, ya que tras ella no dejaron de sucederse otros momentos que anulaban los valores y aprendizajes que había adquirido durante su niñez.

Concluye, de esta forma, que la vida no es como le contaron, que lo que pensaba que era la realidad no era más que un atajo de mentiras y apariencias, y que la verdad habita fuera de esas representaciones. Esta resolución le impulsa a ignorar las voces discordantes que la invitan a no denunciar y a recuperar el poder de decisión sobre su vida: "La opción que todo el mundo le planteaba de denunciar cuando estuviera bien, cuando tuviera otra vida, era absurda. La condición para edificar otra vida pasaba por dejar bien clausuradas las ventanas de lo anterior" (Millás, 2004: 123).

Millás, con el propósito de plasmar al lector este cambio de pensamiento con claridad, llega a comparar el proceso que vive la protagonista con el papel que desarrolla Jack Lemmon en la película Missing. Como Ed Horman ${ }^{6}$, personaje principal del filme, la concejala pasa de haber sido una de ellos a transformarse en víctima de esa misma cultura que antes defendía, una transformación cuyo resultado se traslada al final de la novela:

En Inglaterra, y pese a la dureza del medio, encontró Nevenka un tipo de paz que ni siquiera sabía que existía. Ella hace de aquellos meses un relato tan bien construido que da la impresión de habérselo contado a sí misma cien veces antes de contármelo a mí. Wrexham permanece en su memoria como un espacio mítico en el que se encontró por fin, cara a cara, con la Nevenka que desde algún lugar recóndito de sí misma venía diciéndole: Hay algo que no es como me cuentan (Millás, 2004: 182-183).

6 "Al principio, el personaje no puede creer lo que ve ni oye en cada una de las instancias a la que acude para recabar información. Incluso denuncia inocentemente el atropello, hasta que advierte que lo que le ha ocurrido a su hijo en el Chile de Pinochet es la norma y su desconcierto moral, la excepción" (Millás, 2004: 28). 
Nevenka Fernández se constituye como un personaje arquetípico de la narrativa de Juan José Millás. Aunque se trata de una mujer cuya historia proviene de la realidad, es posible compararla con los protagonistas de sus novelas, ya que, como ellos, decide rechazar los moldes preestablecidos en favor de una nueva identidad, más honesta y fidedigna. Con su relato, los lectores también llegan a plantearse cómo han confeccionado su ideología, sus comportamientos, sus actitudes... aplicando el proceso de extrañamiento de la concejala a ellos mismos. En definitiva, el testimonio de Nevenka es un canto a la autenticidad que anima al público millasiano a reivindicar que, a pesar de todo, hay algo que no es como les dicen.

\section{Conclusiones}

1. A lo largo de toda su trayectoria, Juan José Millás ha desarrollado textos híbridos que combinan los principios periodísticos con herramientas narrativas propias de su ficción, convirtiéndose así en uno de los máximos exponentes del periodismo literario español. El caso más representativo reside en su obra Hay algo que no es como me dicen: el caso Nevenka Fernández contra la realidad, que se constituye como su primera novela de no ficción. En ella, expone su capacidad para elaborar una investigación periodística y ascenderla a la categoría de obra literaria a través de recursos retóricos y poéticos que configuran un estilo propio y diferenciado.

2. Entre las características más comunes que presentan sus trabajos, independientemente del campo al que pertenezcan, destaca de manera significativa el tema de la identidad, con el que Millás despliega su pensamiento. Para este autor, aquello que entendemos como realidad se basa en un pacto social preestablecido que pretende delimitar los comportamientos, ideas e inclinaciones de los individuos. Se trata de un sistema injusto que margina a todas las personas que rechacen, ignoren o traspasen estas fronteras instauradas.

3. Los individuos que protagonizan las historias de Juan José Millás suelen ser personajes que contradicen a estas convenciones. Es el caso de Nevenka Fernández que, aunque en un primer momento responde al prototipo de una joven convencional, consigue romper con la estructura social en la que habita. Nevenka, debido a los episodios reiterados de acoso sexual que ha sufrido, emprende un periplo vital para discernir qué pensamientos provienen de la propia esencia y cuáles forman parte de ese contrato social. Para conseguir este objetivo, es fundamental la noción de extrañamiento, con la que se describe el tránsito de la protagonista de una percepción de la realidad a otra. El extrañamiento no solo aparece en Hay algo que no es como me dicen, sino que se constituye como un sello estilístico de la escritura del autor, tal y como han indicado investigadores como Sobejano (1992) o Ródenas (2006).

4. Nevenka concluye su proceso de extrañamiento con una denuncia pública y judicial a su acosador. Lo que no imagina es que, a pesar de ser la víctima de la situación, será considerada como una verdugo. Esta circunstancia también es común entre los personajes de Millás, ya que, al no responder a las reglas de este pacto social, reciben toda clase de acusaciones con las que se intenta mantener la configuración hegemónica del mundo. Entre los argumentos más comunes empleados para justificar estos cambios de pensamiento se sitúa el de la enajenación. Con ello, Millás efectúa una reflexión en sus textos en torno a la concepción de la locura, un concepto que ha sido empleado como un elemento de corrección y dominio por parte del poder.

5. El autor no solo construye sus novelas, reportajes y columnas con el propósito de entretener a su público. Millás intenta que sus textos sean los detonantes de un cambio de perspectiva en los lectores que derribe determinadas estructuras arbitrarias 
y que tenga consecuencias directas en ámbitos concretos de sus vidas. Por tanto, mediante la lectura de las historias millasianas los receptores pueden empatizar con sus protagonistas y trasladar el proceso de extrañamiento que experimentan los personajes a su propio contexto vital.

\section{Agradecimientos}

Artículo traducido por Sophie Phillips.

\section{Referencias bibliográficas}

Angulo, M. \& Rodríguez, J. M. (2010). Periodismo literario: naturaleza, antecedentes, paradigmas y perspectivas. Madrid: Fragua. Anastasio, P. (2009). Juan José Millás: la realidad y el delirio. En Bou, E., Pittarello, E. (Eds.). (En)claves de la Transición. Una visión de los novísimos. Prosa, poesía, ensayo. (pp. 207-221). Madrid: Iberoamericana Vervuert.

Arenas, G. (2019). Juan José Millás: “Lo que llamamos realidad es un delirio consensuado". En Librotea El País. Recuperado de $<$ https://cutt.ly/2WBbx4h>.

Bértolo, C. (1988). Apéndice a Juan José Millás. En Millás, J.J, Papel Mojado. (pp. 183-213). Madrid: Anaya.

Casals, M. J. (2005). Periodismo y sentido de la realidad: teoría y análisis de la narrativa periodística. Madrid: Fragua.

Chillón, A. (1993). Literatura i periodisme. Valencia: Universitats Valencianes.

Chillón, A. (1999). Literatura y periodismo: una tradición de relaciones promiscuas. Barcelona: Universitat Autónoma de Barcelona.

Cruz, J. (2016). Literatura que cuenta: entrevistas con grandes cronistas de América Latina y España. Madrid: Adriana Hidalgo Editora.

Cuartero, A. (2019). Un periodismo a otra velocidad: el libro como formato periodístico en la nueva generación de periodistas narrativos españoles. En Estudios Sobre El Mensaje Periodístico, 25(2), (pp. 747-766). Recuperado de <https://doi.org/10.5209/ esmp.64800>.

De la Calle, F. (2012). Juan José Millás: “El periodismo no es un género menor que la literatura. En cada reportaje, como en cada novela, te juegas la vida". En Jot Down. Recuperado de <https://cutt.ly/XWBbQvx>.

Elgarte, R. (2011). Consideraciones psicoanalíticas sobre la identidad. En: III Jornadas de Humanidades. Historia del Arte. "Representaciones e identidades". Argentina: Universidad Nacional del Sur. Recuperado de <https://cutt.ly/9Y3QJIk>.

Fernández, M. Á., \& López, A. (2013). Periodismo de inmersión para desenmascarar la realidad. Salamanca: Comunicación Social. Genette, G. (1991). Ficción y dicción. Barcelona: Lumen.

Gie Koh, S. (2011). El juego de la identidad en la obra narrativa de Juan José Millás. [Tesis de doctorado, Universidad Autónoma de Madrid]. Repositorio Institucional - Universidad Autónoma de Madrid. Recuperado de <https://cutt.ly/TWBm16t>. 
Gutiérrez, J. (2009). Acerca del periodismo literario. En Gutiérrez, J. (coord.) De Azorín a Umbral, Un siglo de periodismo literario español. (pp. 25-55). A Coruña: NETBIBLIO.

González Arce, T. (2008). "Periodismo, ficción y realidad: a propósito de Todo son preguntas, El ojo de la cerradura y Sombras sobre sombras de Juan José Millás". En ALPHA: Revista de Artes, Letras y Filosofía, 1(26), (pp. 89-99). Recuperado de <https://cutt. ly/9WBbZcL>.

Iglesia, A. M. (14 de junio de 2017). La historia “verdadera” de Juan José Millás. En The Objective. Recuperado de <https://cutt.ly/ NWBbVi9>.

Kramer, M. (2001). Reglas quebrantables para periodistas literarios. En El Malpensante, Recuperado de <https://cutt.ly/ zWBb8ez>.

Knickerbocker, D. (2007). Dos mujeres en Praga, de Juan José Millás: novela onto-epistemológica. O: el ser como víctima/verdugo. Texturas, 1(7), (pp. 53-69). Recuperado de <https://doi.org/10.14409/texturas.v1i7.2853>.

Lodge, D. (1998). El arte de la ficción. Barcelona: Ediciones Península.

López Pan, F. (2004). "Periodismo literario". Una aproximación desde la "Periodística”. En Retórica, literatura y periodismo: actas del V Seminario Emilio Castelar. Cádiz, noviembre/diciembre de 2004.

Marín, M.R. (2011). El columnismo de Juan José Millás en relación con su narrativa. Análisis de sus columnas en El País (19902008) [Tesis de doctorado - Universidad de Málaga]. Repositorio Institucional - Universidad de Málaga. Recuperado de <https:// cutt.ly/NY3fY0G>.

Montes, A. (23 de octubre de 2012). "Al escribir trato de ordenar la realidad, que es una manera de intentar entenderla." En Faro de Vigo. Recuperado de <https://cutt.ly/PWBb6Eq $>$.

Millas, J. J. (6 de junio 2002). Nevenka. En El País. Recuperado de <https://cutt.ly/jWBnw8I>.

Millás, J. J. (2004). Hay algo que no es como me dicen: El caso Nevenka Fernández contra la realidad. Barcelona: Seix Barral.

Millás, J. J. (26 de febrero de 2021). Nevenka Fernández y el precio de la verdad. En El País Semanal. Recuperado de <https://cutt. ly/vWBnuix>.

Muñoz-Torres, J. R. (2002). Por qué interesan las noticias: un estudio de los fundamentos del interés informativo. Barcelona: Herder.

Prósperi, G. G. (2011). Escenas de metaficción en Juan José Millás. En CELEHIS. Revista del Centro de Letras Hispanoamericanas. 20(22), (pp. 175-197). Recuperado de <https://cutt.ly/EWBnjR5>.

Ródenas, D. (2006). La epistemología de la extrañeza en las columnas de Juan José Millás. En Grohmann, A., Steenmeijer, M. (Coord.) El columnismo de escritores españoles (1975-2005). Madrid: Verbum.

Ródenas, D. (12 de octubre de 2016). Lo cuerdo de la locura. En elPeriódico.com. Recuperado de <https://cutt.ly/2WBnl0n>.

Rojas, R. (2018). Juan José Millás y las nuevas tecnologías audiovisuales. [Tesis de doctorado - Universidad Complutense de Madrid]. Repositorio Institucional - Universidad Complutense de Madrid. Recuperado de <https://cutt.ly/8WBEutd>. 
Sarriá, B. (10 de abril de 2014). Juan José Millás: “La realidad es un delirio consensuado: me da pánico”. 20 Minutos. Recuperado de $<$ https://cutt.ly/mWBnxDR>.

Smith, C. (2012). Like Prisoners in a Cave: A Problematic Search for Identity and Truth in Two Peninsular Novels. En Bulletin of Hispanic Studies. 89(6), (pp. 615-625). Recuperado de <https://doi.org/10.3828/bhs.2012.47>.

Sims, N. (1984). The Literary Journalists. Nueva York: Ballantine Books.

Sobejano, G. (1992) Juan José Millas: fábulas de la extrañeza. En Rico, F. (Coord.) Historia y crítica de la literatura española. Volumen IX: Los nuevos nombres: 1975-1990. Barcelona: Crítica.

Sobejano, G. (2007). Juan José Millás, fabulador de la extrañeza. En Lección de novelas: España, entre 1940 y ayer. Madrid: Mare Nostrum.

Tanner, C. (2016). El periodismo literario como traducción entre dos lecturas: la obra ambidiestra de Juan José Millás. En RECIAL, 7(10). Recuperado de <https://doi.org/10.53971/2718.658x.v7.n10.15348>. 